\title{
New Pyranoanthocyanins Synthesized from Roselle (Hibiscus sabdariffa L.) Anthocyanins
}

\author{
María del Pilar Guzmán-Figueroa, ${ }^{1}$ Ana Eugenia Ortega-Regules, ${ }^{2 *}$ Ana Belén Bautista-Ortín, ${ }^{3}$ \\ Encarna Gómez-Plaza ${ }^{3}$ and Cecilia Anaya-Berríos ${ }^{4}$
}

${ }^{1}$ Departamento de Ingeniería Química, Alimentos y Ambiental, Universidad de las Américas Puebla. Santa Catarina Mártir, 72810 Cholula, Puebla, México.

${ }^{2}$ Departamento de Ciencias de la Salud, Universidad de las Américas Puebla. Santa Catarina Mártir, 72810 Cholula, Puebla, México.

${ }^{3}$ Departamento de Tecnología de Alimentos, Nutrición y Bromatología, Universidad de Murcia, Campus Universitario de Espinardo, s/n, 30100 Espinardo, Murcia, España.

${ }^{4}$ Departamento de Ciencias Químico Biológicas, Universidad de las Américas Puebla. Santa Catarina Mártir, 72810 Cholula, Puebla, México. cecilia.anaya@udlap.mx

Received August 10 $0^{\text {th }}, 2015$; Accepted December 15 ${ }^{\text {th }}, 2015$.

\begin{abstract}
Six new pyranoanthocyanins were synthesized through the reaction between dephinidin-3-sambubioside and cyanidin-3-sambubioside, extracted from roselle calyxes, with 4-vinylphenol, acetone and 2-butanone. The reaction products were characterized by liquid chromatography coupled to mass spectrometry (HPLC-TOF-MS), ultraviolet-visible spectroscopy (UV/Vis) and high-performance liquid chromatography. Those new pigments belong to the families of pinotins and methylpyranoanthocyanins and show a hypsochromic shift, which results in a more orange colour compared to the red hue of the original anthocyanins. Therefore, these compounds could be used to obtain new colorants more stable against certain factors such as $\mathrm{pH}$.

Key words: pyranoanthocyanins; roselle; 4-vinylphenol; acetone; pinotins; methylpyranoanthocyanins.
\end{abstract}

\section{Introduction}

Roselle (Hibiscus sabdariffa L.) is an annual shrub which belongs to family Malvaceae and grows in regions with dry tropical weather, countries like China, Egypt, Sudan, Thailand, Senegal, Tanzania and Mexico. It is known by different synonyms and vernacular names around the world and its cultivation has diverse purposes, but the most important one is to produce infusions from the calyx of their flowers [1]. Nevertheless, because of its brilliant red colour and unique flavor, its calyxes are also used to make jellies, jams, sauces, wines and beverages [2-4].

Recently there has been increasing interest in this due to their beneficial health effects and there are studies about its antihyperlipidemic, antihypertensive, antypyretic, apoptotic and antioxidant activity $[5,6]$. Thus, roselle could not only be used as nutrient or colorant but also as a functional food ingredient [7]. The responsible compounds for the brilliant colour and some of mentioned activities are anthocyanins.
Resumen. Se sintetizaron seis nuevas piranoantocianinas a través de la reacción de la delfinidina-3-sambubiósido y cianidina-3-sambubiósido, extraídas de los cálices de flor de jamaica, con 4-vinilfenol, acetona y 2-butanona. Los productos de la reacción fueron caracterizados por cromatografía líquida acoplada a espectrometría de masas (HPLCTOF-MS), espectroscopia ultravioleta-visible (UV/Vis) y cromatografía líquida de alta resolución (HPLC). Estos nuevos compuestos pertenecen a las familias de las pinotinas y metilpiranoantocianinas, los cuales muestran un desplazamiento hipsocrómico, lo que genera pigmentos de color más naranja en comparación con el color rojo de las antocianinas originales. Por lo que, podrían ser utilizados para obtener nuevas tonalidades para colorantes más estables ante ciertos factores como el $\mathrm{pH}$.

Palabras clave: piranoantocianinas; Jamaica; 4-vinilfenol; acetona; pinotinas; metilpiranoantocianinas.

Anthocyanins constitute a major polyphenolic family of compounds widespread in the plant kingdom; they are of interest for the food industry as potential replacements for banned dyes [8]. However, their application has been limited because of their low stability to several factors [9-16]. Consequently, diverse research groups have been searching for new anthocyanin-based natural colorants that have better colour and stability properties [17].

In 1996, Cameira dos Santos et al. [18] isolated a class of anthocyanin-derived pigment. After that, Fulcrand et al. [19] presented a structure with an additional pyrano ring between $\mathrm{C}-4$ and the hydroxyl group at $\mathrm{C}-5$ of a malvidin core, demonstrating that this compound was the result of the reaction of malvidin-3-glucoside and 4-vinylphenol [20]. This pyranoanthocyanin family has been named hydroxyphenyl-pyranoanthocyanins, and their formation happens due to both hydroxycinnamic acids and 4-vinylphenols reacting with free anthocyanins. The family is also known as pinotins [21] since they were firstly isolated from Pinotage wines [22]. Later, those compounds were 
discovered in other varieties of wine [23-25] and in some fruits juices [26]. Relating to the characteristics of the pinotins family, they show less polarity and a hypsochromic shift in relation to the original anthocyanins [19], plus, a higher stability against several factors such as $\mathrm{pH}[27]$.

On the other hand, Lu and Foo [28] observed the formation of new compounds when blackcurrant anthocyanins were extracted with aqueous acetone, proposing that this compounds were the result of the nucleophilic reaction with acetone. These derivatives named methylpyranoanthocyanins, show a yellow-orangish colour as a result of their hypsocromic effect.

Therefore, pyranoanthocyanins could be formed by the reaction of anthocyanins and small molecules $[29,30]$. Their importance lies in the fact that they have shown to have a greater colour stability against $\mathrm{pH}$ changes and bleaching by sulfur dioxide than the original anthocyanins [31] and higher colour at similar concentration. Thus, since their discovery, pyranoanthocyanins have received much attention. Nevertheless, isolation and characterization of such pigments has proved to be difficult because of their concentration in food substrates is much lower than original anthocyanin. For this reason, they have been synthesized in model solutions for being characterized [32, 33].

The aim of the present work was to obtain new anthocyanin derived compounds which could expand the colorant range of food colorants since they exhibit different colors than starting material. For that reason, we synthesize and characterize six new pyranoanthocyanins related to the families of hydroxyphenyl-pyranoanthocyanins and methylpyranoanthocyanins. They were obtained as a result of the reaction of anthocyanins extracted from roselle (Hibiscus sabdariffa $\mathrm{L}$.) calyxes with 4-vinylphenol, acetone and 2-butanone.

\section{Results and discussion}

\section{Extraction of anthocyanins from roselle calyxes}

Usually, roselle extracts contain four anthocyanins [34]: delphinidin-3-sambubioside (1), delphinidin-3-glucoside, cyanidin-3-sambubioside (2) and cyanidin-3-glucoside, but the majority ones are the two sambubiosides, while the concentration of glucosides is less than 7\% [35]. In this study, the roselle extract which has been purified using Amberlite XAD-7, showed only two of the four common anthocyanins in roselle extracts. This mixture of delphinidin-3-sambubioside (1) and cyanidin-3-sambubioside (2) (Fig. 1) was used for the synthesis of pyranoanthocyanins. Under the HPLC conditions used, delphinidin-3-sambubioside (1) showed an absorption peak at 526 nm, while cyanidin-3-sambubioside (2), at $518 \mathrm{~nm}$ (Fig. 2a).

\section{Synthesis of hydroxyphenyl-pyranoanthocyanins (3) and (4)}

The formation of these products was achieved using the conditions proposed by Fulcrand et al. [19], which consist of reacting anthocyanin mixture with 4-vinylphenol in acid-aqueous media. Reaction was performed during $24 \mathrm{~h}$, and passing that time, the presence of anthocyanins was not observed. Products were confirmed by HPLC-TOF-MS. It was observed the $[\mathrm{M}]^{+}$ion located in $713.3 \mathrm{~m} / \mathrm{z}$ for (3) and in $697.3 \mathrm{~m} / \mathrm{z}$ for (4), which match with the molecular weight for the proposed structure. Likewise the fragmentation pattern of anthocyanins, these pinotins showed [M-294] ion due to loss of sambubioside unit: $419.3 \mathrm{~m} / \mathrm{z}$ for (3) and $403.2 \mathrm{~m} / \mathrm{z}$ for (4).

The newly synthesized pyranoanthocyanins show different spectroscopic characteristics, compared with their anthocyanic counterparts. It was observed a hypsochromic shift, in which the pinotin (3) shows a peak of absorption at $503 \mathrm{~nm}$, while pinotin (4) at $501 \mathrm{~nm}$, therefore they present a hypsochromic shift of 23 and $17 \mathrm{~nm}$, for (3) and (4), respectively (Fig. 2b). Table 1 summarizes the data for anthocyanins and pyranoanthocyanins.

\section{Synthesis of methylpyranoanthocyanins (5) and (6)}

Two members of the family of pyranoantocyanins were synthesized through the nucleophilic addition of acetone, when reacted with the methanolic mixture of anthocyanins from roselle calyxes. The reaction was monitored by HPLC during $120 \mathrm{~h}$. It is worth mentioning that the ratio acetone:anthocyanin was an important factor for yield, reaching better yields with a 30:1 ratio (volume).

The resulting compounds were purified using a column Sephadex LH-20 and analyzed by HPLC and HPLC-TOF-MS. The molecular weight obtained, coincided with proposed structure and the presence of the ions [M] $]^{+}$and [M-294] was exhibited, demonstrating the characteristic fragmentation pattern of anthocyanins.

Methylpyranoanthocyanins show structural similarities with vitisins. It has been reported that vitisin A and B have hypsochromic shifts of $18-19 \mathrm{~nm}$ and 36-39 nm, respectively, depending on solvent. Bakker and Timberlake [36] proposed that hypsochromic shift was probably caused by the delocalization of the positive charge on $\mathrm{C}$ ring, which could be caused by resonance and for its partial residence on the oxygen atom of the newly formed $\mathrm{D}$ ring. They also proposed that the unusual shoulder observed in the UV spectra of vitisin is due to C-4 substitution. In the same way, the methylpyranoanthocyanins (5) and (6) have absorption peaks in 478 and $475 \mathrm{~nm}$ (Fig. 2c), showing a hypsochromic shift related to the original anthocyanins, but higher than that observed on vitisins (43-48 nm). Also these compounds show an unusual band in 354 and $340 \mathrm{~nm}$, which is not present in anthocyanins and nor in pinotins.

\section{Synthesis of methylpyranoanthocyanins (7) and (8)}

The reaction products were certainly identified as methylpyranoanthocyanins-derived since they had similar retention times (Table 1) and UV spectrum than methylpyranoanthocyanins (5) and (6) (Fig. 2d). Furthermore, molecular weight of methylpyranoanthocyanins (7) and (8) is consistent with the insertion of 


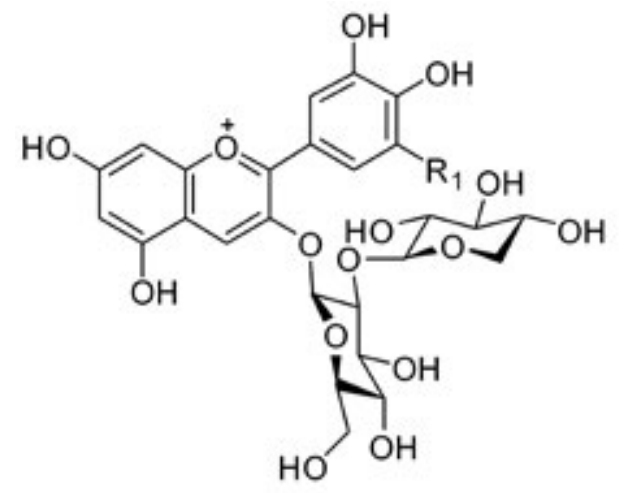

1, $\mathrm{R}_{1}=\mathrm{OH}$

2, $\mathrm{R}_{1}=\mathrm{H}$

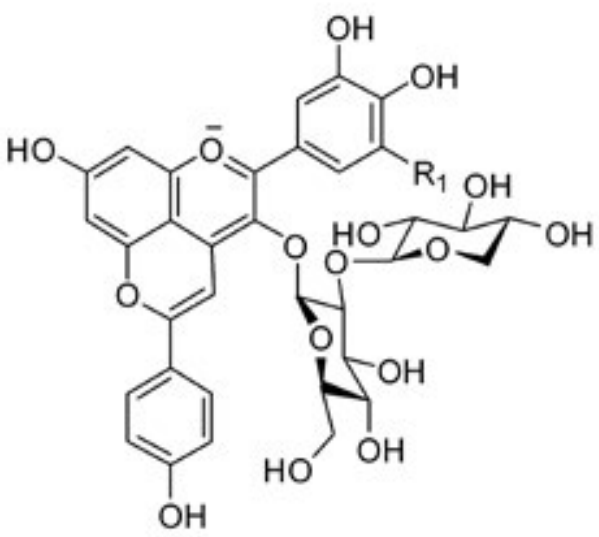

3. $\mathrm{R}_{1}=\mathrm{OH}$

4, $\mathrm{R}_{1}=\mathrm{H}$,

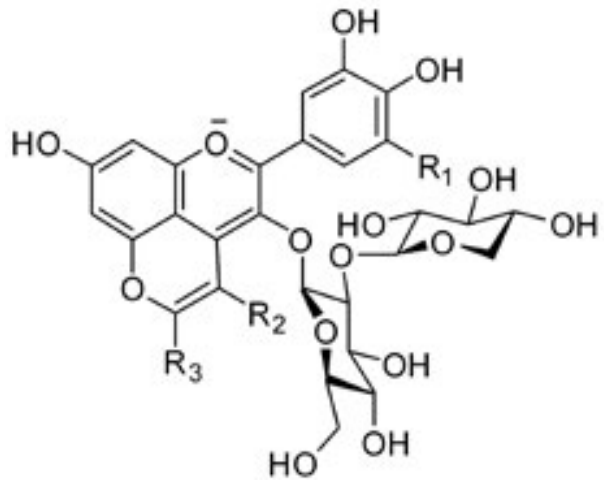

5, $\mathrm{R}_{1}=\mathrm{OH}, \mathrm{R}_{2}=\mathrm{H}, \mathrm{R}_{3}=\mathrm{CH}_{3}$

6, $\mathrm{R}_{1}=\mathrm{H}, \mathrm{R}_{2}=\mathrm{H}, \mathrm{R}_{3}=\mathrm{CH}_{3}$

7, $\mathrm{R}_{1}=\mathrm{OH}, \mathrm{R}_{2}=\mathrm{CH}_{3}, \mathrm{R}_{3}=\mathrm{CH}_{3}$

8, $\mathrm{R}_{1}=\mathrm{H}, \mathrm{R}_{2}=\mathrm{CH}_{3}, \mathrm{R}_{3}=\mathrm{CH}_{3}$

Fig. 1. Structures of the anthocyanins present in roselle (Hibiscus sabdariffa L.) calyxes extract and their derived pyranoanthocyanins.

2-butanone molecule. According to mechanism proposed by $\mathrm{Lu}$ and Foo [28], there is a dehydration (-18 units) and oxidation (-2 units) plus molecular weight of 2-butanone (+72.1 units); thus, there is a difference among molecular weight of anthocyanins (1) and (2) and methylpyranoanthocyanins (7) and (8) of 52 units. Besides, these compounds show the same characteristics of fragmentation pattern than other pyranoanthocyanins, that is, the presence of the ions $[\mathrm{M}]^{+}$and [M-294].

It is important to notice that any pyranoanthocyanin have a retention time close to anthocyanins (Table 1), indicating different polarity due to the formation of the new ring. Nevertheless, despite the retention times are close, they are longer for pyranoanthocyanins (Table $1 ; 3-8$ ) respect to precedent anthocyanins (Table 1;1 and 2). All pyranoanthocyanins synthetized in this work had a hypsochromic shift that made them more orange in comparison with the red hue of the original anthocyanins. On the other hand, the differences between delphinidin and cyanindin-derivatives of the same compound are lesser than the difference between anthocyanins; in this case, the B-ring pattern could not be a determinant factor for wavelength of maximum absorbance.

\section{Experimental}

\section{Chemicals}

Delphinidin-3-sambubioside (1) and cyanidin-3-sambubioside (2) were isolated from sun-dried roselle calyxes (Hibiscus sabdariffa L.) grown in Chiautla de Tapia, Puebla (980 m.a.s.l.). 
a)
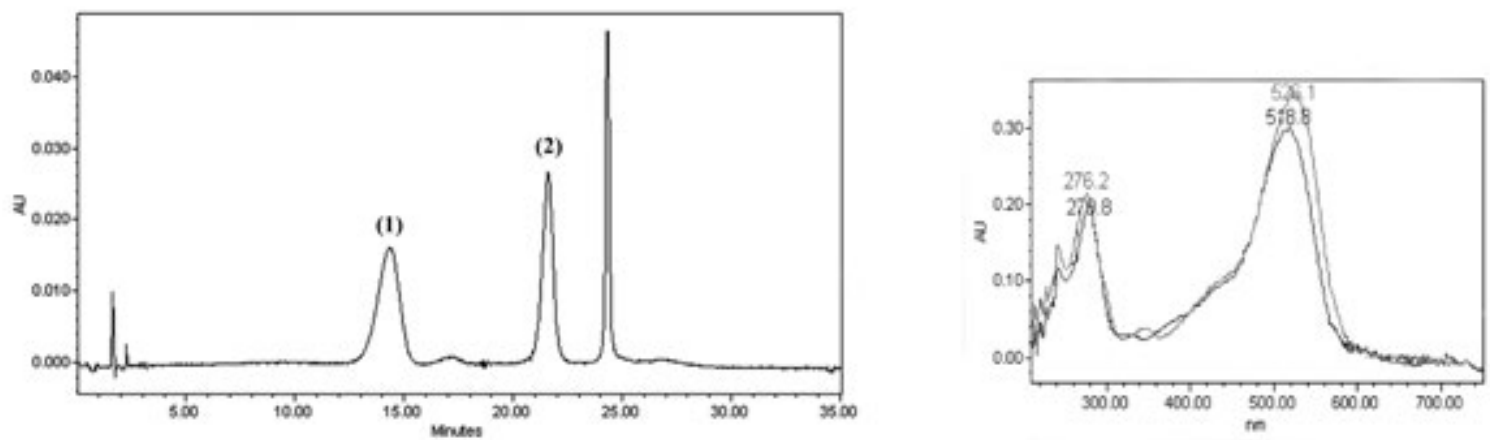

b)
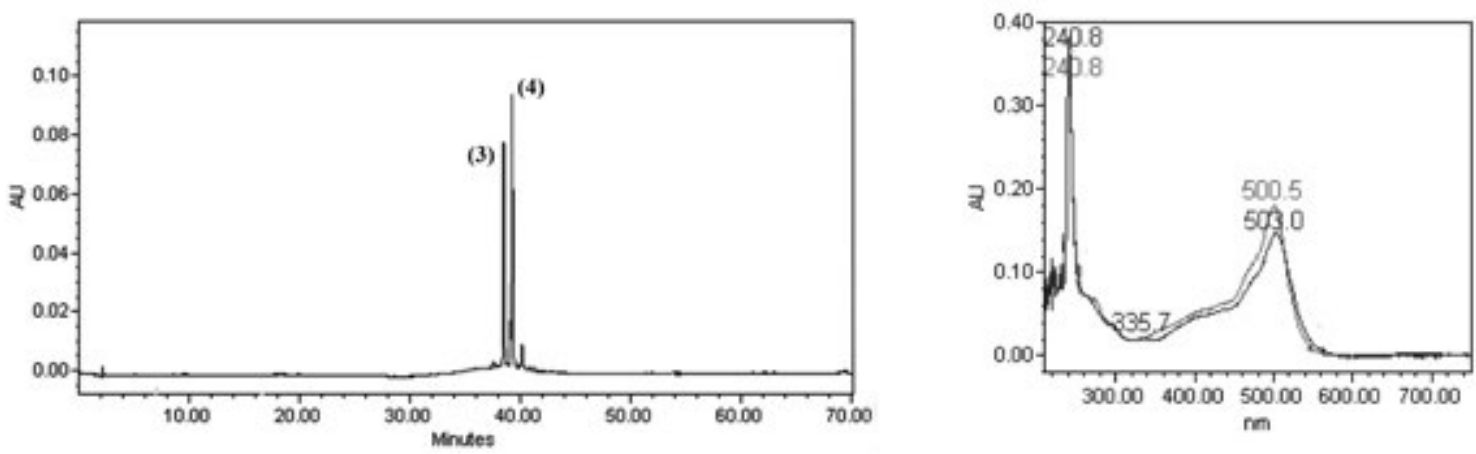

c)
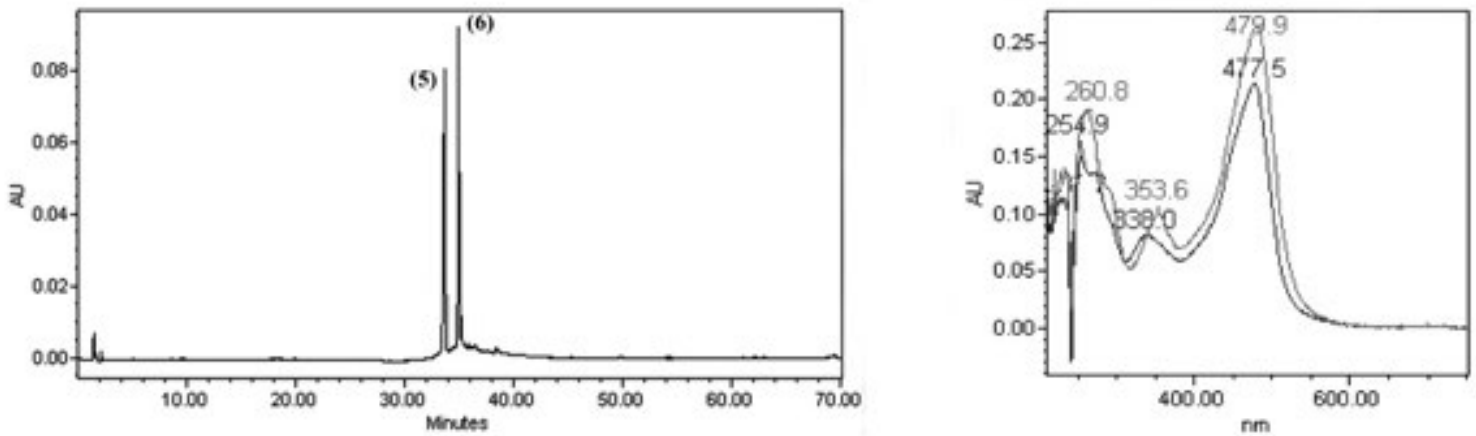

d)
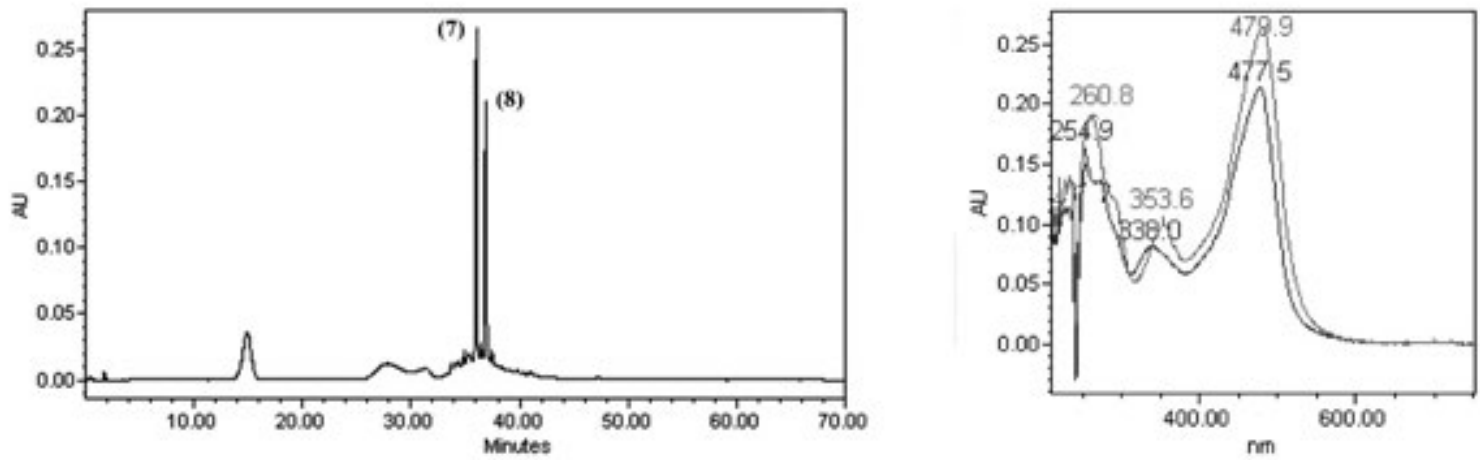

Fig. 2. HPLC chromatograms which evidence the presence of anthocyanins $(520 \mathrm{~nm})$ and pyranoanthocyanins (480 $\mathrm{nm})$. UV-spectra for a) mixture of anthocyanins (dephinidin-3-sambubioside (1) and cyanidin-3-sambubioside (2)); b) hydroxyphenyl-pyranoanthocyanins (3) and (4); c) methylpyranoanthocyanins (5) and (6); d) methylpyranoanthocyanins (7) and (8). 
Table 1. Spectroscopic and chromatographic data from roselle anthocyanins and their derivated pyranoanthocyanins.

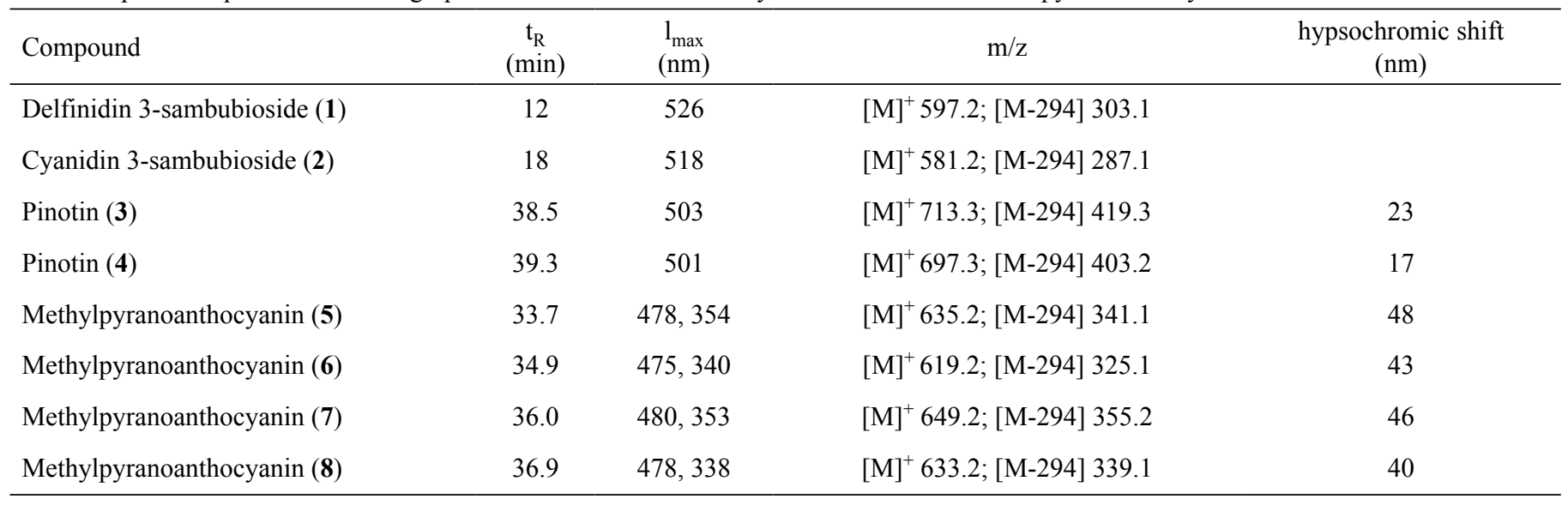

Amberlite XAD-7 and Sephadex LH-20 were purchased from Sigma-Aldrich. Water and acetonitrile used in chromatography assays were HPLC-grade and purchased from Merck. Formic acid $>88 \%$, acetone reactive grade, clorhidric acid, 2-butanone and 4-vinylphenol were purchased from Sigma-Aldrich. Hexane, ethyl acetate and methanol used on columns were industrial grade double distilled.

\section{Anthocyanin extraction}

Roselle calyxes (Hibiscus sabdariffa L.) were previously grounded and then macerated using methanol for $2 \mathrm{~h}$, using a ratio $40 \mathrm{~g} / 200 \mathrm{~mL}$. The extract obtained was filtrated, vacuum-dried, and adsorbed in Amberlite XAD-7 (64 g). The adsorbed resin was packed on a column $(3.2 \times 45 \mathrm{~cm})$, then eluted with acid water $(2 \mathrm{~L}, 0.01 \% \mathrm{HCl})$, hexane $(1 \mathrm{~L})$, ethyl acetate $(1$ $\mathrm{L})$, and acid methanol $(800 \mathrm{~mL}, 0.01 \% \mathrm{HCl})$. The water, hexane and ethyl acetate fractions were discarded; meanwhile, the methanol fraction was vacuum-distilled for obtaining a mixture composed by delphinidin-3-sambubioside (1) and cyanidin-3-sambubioside (2).

\section{Chromatographic profile}

HPLC of Anthocyanins. The mixture obtained above, was analyzed by HPLC Waters 600 equipped with $20 \mu \mathrm{L}$ loop, using a reverse phase column C18 LiChroCART ( $25 \times 0.4 \mathrm{~cm}, 5 \mu \mathrm{m})$. A gradient was established using acetonitrile (A) and $4.5 \%$ formic acid (B): isocratic 9:91 (A:B) for $25 \mathrm{~min}, 26-28 \mathrm{~min}, 100: 0$ $(\mathrm{A}: \mathrm{B})$ and $28-30 \mathrm{~min}, 9: 91(\mathrm{~A}: \mathrm{B})$ at a flow rate of $1.5 \mathrm{~mL} / \mathrm{min}$. Detection was carried out using a Waters 996 PDA detector at $520 \mathrm{~nm}$.

HPLC of pyranoanthocyanins. Products obtained were analyzed using the same column and flow rate described earlier, but the gradient was changed: isocratic 9:91 (A:B) for $20 \mathrm{~min}$, 20-25 min, 5:95 (A:B); 25-65 min 100:0 (A:B), 65-70 min, 9:91 (A:B). Detection was carried out at $480 \mathrm{~nm}$.

HPLC-TOF-MS. Pyranoanthocyanins were analyzed by HPLC Agilent 1200 series coupled to Agilent 6220 series timeof-flight mass spectrometer (TOF-MS) system. Mass spectra were acquired using an electrospray source in positive mode (ESI+), from $200-1200 \mathrm{~m} / \mathrm{z}$. A gradient was established using acetonitrile (A) and $4.5 \%$ formic acid (B) using a C18 column with a flow rate of $0.8 \mathrm{~min} / \mathrm{mL}$ in the following conditions: $9: 91$ (A:B) at $0 \mathrm{~min}, 0-30 \mathrm{~min}, 60: 40(\mathrm{~A}: \mathrm{B}), 30-32 \mathrm{~min}, 0: 100(\mathrm{~A}: \mathrm{B})$, isocratic 0:100 (A:B) for $5 \mathrm{~min}, 37-39 \min$ 9:91 (A:B).

\section{Synthesis of hydroxyphenyl-pyranoanthocyanins (3) and (4)}

A mixture $(150 \mathrm{mg})$ of the extracted anthocyanins was dissolved in $40 \mathrm{~mL}$ of a solution of aqueous $0.001 \mathrm{M} \mathrm{HCl}$, using a flask provided with a stirrer. Then $1 \mathrm{~mL}$ of 4 -vinylphenol was added. The mixture was stirred for $24 \mathrm{~h}$. After this time, the mixture was filtrated and was adsorbed in a Sephadex LH-20 column $(1 \times 9 \mathrm{~cm})$, then was eluted using water. The resulting fraction was lyophilized.

\section{Synthesis of methylpyranoanthocyanins (5) and (6)}

Using a flask provided with a stirrer, $200 \mathrm{mg}$ of mixture of anthocyanins were dissolved in $6 \mathrm{~mL}$ of methanol and $14 \mathrm{~mL}$ of acetone. Reaction mixture was stirred for $120 \mathrm{~h}$; then the solvent was vacuum-distilled and absorbed in a Sephadex LH-20 $(1 \times 9 \mathrm{~cm})$ which was eluted using water. The resulting fraction was lyophilized.

\section{Synthesis of methylpyranoanthocyanins (7) and (8)}

Using a stirred-flask, $200 \mathrm{mg}$ of mixture of anthocyanins were dissolved in $6 \mathrm{~mL}$ of methanol and $14 \mathrm{~mL}$ of 2-butanone. The reaction and purification were developed under the same conditions than those described for the synthesis of methylpyranoanthocyanins (5) and (6).

\section{Conclusions}

Nucleophilic reactions between roselle anthocyanins and 4-vinylphenol, and some ketones were achieved. These reactions 
generate products with different spectral and chromatographic properties than those from original anthocyanins.

Roselle anthocyanins react with 4-vinylphenol to generate hydroxyphenyl-pyranoanthocyanins derivatives. This pyranoanthocyanin family can be synthesized faster than other pyranoanthocyanins, and they might be used as pigments in medium- and low-acid food.

On the other hand, the anthocyanin reaction with acetone produces methylpyranoanthocyanins (5) and (6), which are relatively fast synthesized. We observed that the relation anthocyanin-acetone-solvent is an important factor to obtain them, as confirmed from preliminary ratios assayed for the reaction (10:1, 20:1, 30:1, 40:1, 50:1, and 80:1, acetone:anthocyanin), and the best was selected in terms of HPLC signal intensity. These compounds had a more pronounced hypsocromical effect showing a yellow-orange colour; in this way, they expanded the colour range in their application as food colorants.

Methylpyranoanthocyanins (7) and (8) were synthesized in the same manner and they had similar spectral properties, nevertheless further investigations are necessary to determine steric hindrance on pyranoanthocyanin formation when ketone chain is increased.

Pyranoanthocyanins are no just more stable than anthocyanins but also they display more colours depending on their structure, we proposed that methodologies used here could expand the structural variety of pyranoanthocyanins.

\section{Acknowledgements}

The authors would like to thank CONACYT for financial support through the project 153594, and scholarship 207757

\section{References}

1. Aurelio, D.-L.; Edgardo, R. G.; Navarro-Galindo, S. Int. J. Food Sci. Tech. 2008, 43, 322-325.

2. D’Heureux-Calyx, F.; Badrie, N. Food Serv. Tech. 2004, 4, 141148.

3. Alobo, A. P.; Offonry, S. U. J. Inst. Brew. 2009, 115, 91-94.

4. Duangmal, K.; Saicheua, B.; Sueeprasan, S. LTW-Food Sci. Technol. 2008, 41, 1437-1445.

5. Carvajal-Zarrabal, O.; Barradas-Dermitz, D. M.; Orta-Flores, Z.; Hayward-Jones, P. M.; Nolasco-Hipólito, C.; Aguilar-Uscanga, M. G.; Miranda-Medina, A.; Bujang, K. B. J. Pharmacol. Exp. 2012, 4, 25-39.

6. Ali, B. H.; Wabel, N. A.; Blunden, G. Phytother. Res. 2005, 19, 369-375.

7. Chiou, D.; Langrish, T. A. G. J. Food Eng. 2007, 82, 84-91.
8. Rodriguez-Saona, L. E.; Giusti, M. M.; Wrolstad, R. E. J. Food Sci. 1998, 63, 458-465.

9. Özkan, M. Food Chem. 2002, 78, 499-504.

10. Bakhshayeshi, M. A.; Khayami, M.; Heidari, R.; Jamei, R. Pak. J. Biol. Sci. 2006, 9, 428-433.

11. Nikkhah, E.; Khayamy, M.; Heidari, R.; Jamee, R. J. Biol. Sci. 2007, 7, 1412-1417.

12. Nikkhah, E.; Khayami, M.; Heidari, R.; Bernousi, I. Res. J. Biol. Sci. 2008, 3, 80-84.

13. Kader, F.; Rovel, B.; Girardin, M.; Metche, M. J. Sci. Food Agric. 1997, 74, 31-34.

14. Kader, F.; Irmouli, M.; Nicolas, J. P.; Metche, M. J. Food Sci. 2002, 67, 910-915.

15. Calderón, A. A.; García-Florenciano, E.; Muñoz, R.; Ros Barceló, A. Vitis 1992, 31, 139-147.

16. Li, J.; Jiang, Y. Molecules 2007, 12, 745-758.

17. Wrolstad, R.; Durst, R. W.; Lee, J. Trends Food Sci. Tech. 2005, 16, 423-428.

18. Cameira-dos-Santos, P. -J.; Brillouet, J. -M.; Cheynier, V.; Moutounet, M. J. Sci. Food Agric. 1996, 70, 204-208.

19. Fulcrand, H.; Cameira dos Santos, P. -J.; Sarni-Manchado, P.; Cheynier, V.; Favre-Bonvin, J. J. Chem. Soc., Perkin Trans. 1996, 7, 735-739.

20. Rentzsch, M.; Schwarz, M.; Winterhalter, P. Trends Food Sci. Tech. 2007, 18, 526-534.

21. He, F.; Liang, N. -N.; Mu, L.; Pan, Q. -H.; Wang, J.; Reeves, M. J.; Duan, C. -Q. Molecules 2012, 17, 1483-1519.

22. Schwarz, M.; Jerz, G.; Winterhalter, P. Vitis 2003, 42, 105-106.

23. Wang, H.; Race, E. J.; Shirikhande, A. J. J. Agric. Food Chem. 2003, 51, 7989-7994.

24. Rentzsch, M.; Schwarz, M.; Winterhalter, P.; Hermosín-Gutiérrez, I. J. Agric. Food Chem. 2007, 55, 4883-4888.

25. Vivar-Quintana, A. M.; Santos-Buelga, C.; Rivas-Gonzalo, J. C. Anal. Chim. Acta 2002, 458, 147-155.

26. Hillebrand, S.; Schwarz, M.; Winterhalter, P. J. Agric. Food Chem. 2004, 52, 7331-7338.

27. Schwarz, M.; Winterhalter, P. Tetrahedron Lett. 2003, 44, 75837587.

28. Lu, Y.; Foo, L. Y. Tetrahedron Lett. 2001, 42, 1371-1373.

29. Alcalde-Eon, C.; Escribano-Bailón, M. T.; Santos-Buelga, C.; Rivas-Gonzalo, J. C. Anal. Chim. Acta 2006, 563, 238-254.

30. de Freitas, V.; Mateus, N. Anal. Bioanal. Chem 2011, 401, $1463-$ 1473.

31. Oliveira, J.; Fernandes, V.; Miranda, C.; Santos-Buelga, C.; Silva, A.; de Freitas, V.; Mateus, N. J. Agric. Food Chem. 2006, 54, 6894-6903.

32. Håkansson, A. E.; Pardon, K.; Hayasaka, Y.; de Sa, M.; Herderich, M. Tetrahedron Lett. 2003, 44, 4887-4891.

33. Mateus, N.; de Pascual-Teresa, S.; Rivas-Gonzalo, J. C.; Santos-Buelga, C.; de Freitas, V. Food Chem. 2002, 76, 335-342.

34. Palé, É.; Kouda-Bonafos, M.; Nacro, M. C. R. Chim 2004, 7, $973-$ 980.

35. Hong, V.; Wrolstad, R. E. J. Agric. Food Chem. 1990, 38, 708-715.

36. Bakker, J.; Timberlake, C. F. J. Agric. Food Chem. 1997, 45, 35-43. 